\title{
RESEARCHES REGARDING THE MODERNIZING OF HYDRO- TECHNICAL DESIGNING THROUGH ASSISTED DESIGNING
}

\author{
Marin Silviu Nan \\ professor, University of Petrosani \\ 20 University Street, 332006, Petrosani, Romania, e-mail: nan.marins@gmail.com \\ Iosif Kovacs \\ professor, University of Petrosani \\ 20 University Street, 332006, Petrosani, Romania, e-mail: kovacsi@mail.com
}

Aurelian Horia Nicola

lecturer, University of Petrosani

20 University Street, 332006, Petrosani, Romania, e-mail: aurelian.nicola@yahoo.com

Daniel Cosmin Vitan

assistant lecturer, University of Petrosani

20 University Street, 332006, Petrosani, Romania, e-mail: vitan.daniel.cosmin@gmail.com

\begin{abstract}
Hydro-technical works differ from the other engineering constructions due to the fact that they are subject to water influence. In nature, water exerts mechanical, physical, chemical and biological actions. Water's mechanical action is expressed by hydrostatic pressure and dynamic pressure. Hydrostatic pressure represents the main stress, which generally determines the form and size of hydro- technical construction. As a rule, dynamic pressure is exerted by water in motion upon the elements it enters into contact. The present paper present with the dimensioning of the pipe segments, focusing on the joining of these and the simulation in conditions as close as possible to reality, of the water pipe, within the help of finite element analysis, but also with specialized simulation software. After analysis, verification and fabrication of the pipe segments, they must be transported and mounted on the inclined plane. The constructive solution of the transport sleigh for the pipes transported on the inclined plane is also verified at requests with the help of the Solid Work software, in order to be able to use it in safe conditions.
\end{abstract}

Keywords: modernizing hydro-technical, assisted designing hydro-technical, underground water transport

\section{Introduction}

With the progress of science and technique, the range and amount of theoretical and practical knowledge has also increased. In accordance, the number of unaccomplished projects caused by ignorance and lack of experience has continually decreased. Although important achievements have been registered in the field of hydro-technical constructions, nonetheless, it is not safe to assert that the quality of such works is flawless. 
Hydro-technical works are complex works. They exert an important influence upon the neighbouring areas, both as far as their general development is concerned and as far as the ecological aspect is concerned. They share different roles and importance so that their damaging or destruction may result in various consequences. The consequences may range from reduced or insignificant to real catastrophes as in the case of the dams that deal with huge water accumulations. The poor organizing of designing, the inefficient collaboration among the designing departments and the incomplete use of documentary stuff represent aspects that influence negatively the quality of these works.

The quality of hydro-technical works is influenced by a series of factors. Negative factors manifest themselves through the use of improper stuff and equipment and through employing or using incompetent personnel, lacking experience or seriousness. Negative factors also include failure to observe the execution schedules that concern the construction and the operations as well as failure to observe the stipulations and technologies shown in the project and specifications.

\section{Quality of hydro-technical works}

The size and shape of hydro-technical works are closely connected with the natural characteristics of the location, which might be topographic, geologic and hydrologic. Generally, these characteristics do not repeat in the case of other works due to the fact that each hydro-technical work is an original one. Even the designing and execution of such works do not copy patterns but consider the local specific conditions of each location.

During the last years, $\mathrm{CAD} / \mathrm{CAM} / \mathrm{CAE}$ world has been shaken by serious changes that all targeted the increase of the efficiency of designing activities. A series of new phrases come out in the domain of computer-assisted designing: integrated system, competition engineering or serial engineering that have as a goal the defining of entirely new concepts and as objectives the improvement of designing activities.

The final result asserts that a product may be designed, tested and experimented within a short time, with decreased financial contributions, and, yet, with high quality results. Meanwhile, computer-assisted designing remarkably improves the productivity of designing through special environments for metalboard constructions, welding and pipes (Bâla, 1981).

By way of computer-assisted designing two basic issues of carrying out hydro-technical works have been solved. The first one regards the optimal size of power tunnels. The second one regards the modernizing of the technology that allows the carrying out of hydro-technical works through designing the devices for increasing productivity and decreasing execution costs (Stematiu, 2008).

\section{Optimal size of power tunnels}

Relying on the calculation relations, a program has been conceived in MathCAD with a view to settling the optimal size of power tunnels.

During the first stage, the available hydraulic powers of the hydro-electric planning for installed flows between 2 and $140 \mathrm{~m}^{3} / \mathrm{s}$ and gross falls between 50 and $300 \mathrm{~m}$ have been determined. Gross fall represents the level difference between the surge chamber and the spillage lake or the level of the turbine's tail race.

$$
\begin{gathered}
\lambda_{i}=\frac{64}{R e_{i}} \rightarrow \lambda_{1}=0.235, \lambda_{2}=0.028 \\
R e_{i}=\frac{4 \cdot Q_{i}}{\pi \cdot d_{i} \cdot v}
\end{gathered}
$$


where: $\lambda_{i}$ - coefficient of uniform load loss distributed along the length of the pipe; $R e$-Raynolds number; $Q_{i}$ - installed flow; $d_{i}$ - inner diameter of the pipe; $v$ - kinematic viscosity of water.

Hydraulic powers result for a water flow speed through the pipe representing $5 \mathrm{~m} / \mathrm{s}$ in accordance with a laminar flow. The slope angle of the power tunnel compared with the horizontal line is at 32 degrees. Along the route, there are two bends and two butterfly valves. In order to see the influence of the flow speed upon the hydraulic losses in the pipe similar diagrams have been drawn out for a flow speed of $2.5 \mathrm{~m} / \mathrm{s}$, calculated with:

$$
h_{p_{i}}=0.0826 \cdot \frac{\lambda_{i} \cdot L_{j} \cdot\left(Q_{i}\right)^{2}}{\left(d_{i}\right)^{2}},[\mathrm{~m}]
$$

These diagrams allow the rapid determination of the hydraulic power at the level of the turbine as well as of the total hydraulic losses along the power tunnels. These sizes are calculated depending on the installed flow and the gross fall of the hydro-electrical planning, which increases step by step, every $50 \mathrm{~m}$. In the case of intermediary gross falls, the rule of three may be applied. For installed flows less than $10 \mathrm{~m}^{3} / \mathrm{s}$ there are quite important losses of hydraulic power along the pipe. They represent over $20 \%$ and may reach $80 \%$ in the case of a flow of $2 \mathrm{~m}^{3} / \mathrm{s}$, irrespective of the fall of the hydro-electrical planning. As a result, for flows that are less than $20 \mathrm{~m}^{3} / \mathrm{s}$, it is required to decrease flow speed through increasing the diameter of the pipe.

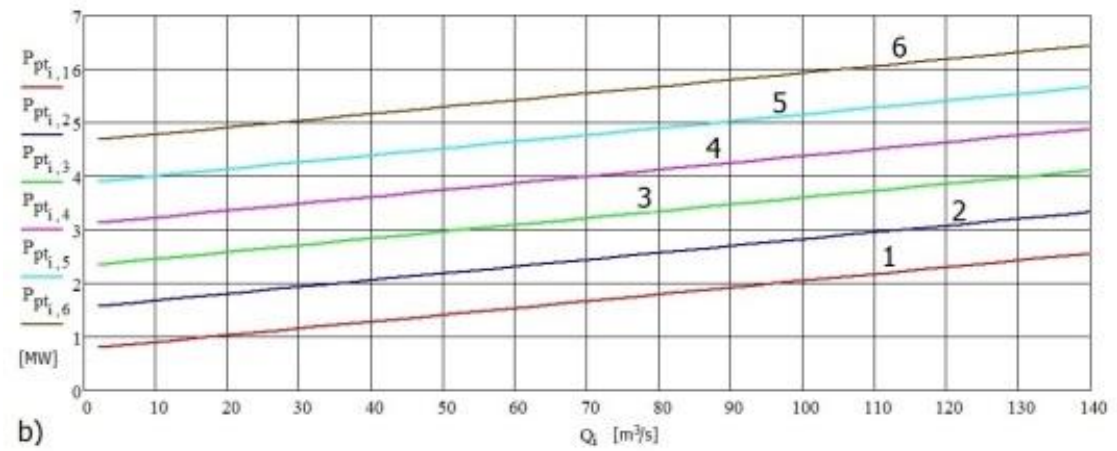

b)

Q $\left[\mathrm{m}^{3 / \mathrm{s}}\right]$

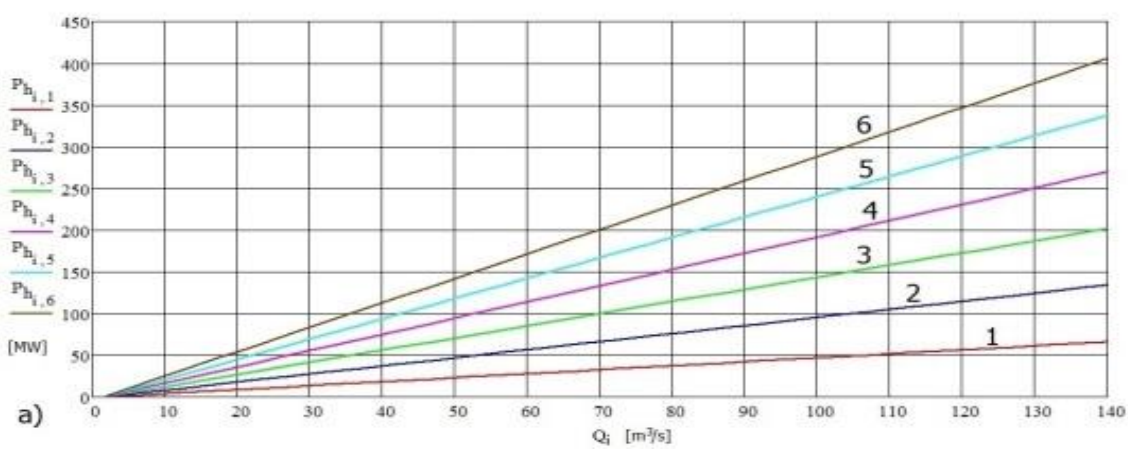

Figure 1. Power variation. $a$ - hydraulic power; $b$-total hydraulic losses: 1 - gross fall of $50 \mathrm{~m} ; 2$ gross fall of $100 \mathrm{~m} ; 3$ - gross fall of $150 \mathrm{~m} ; 4$ - gross fall of $200 \mathrm{~m} ; 5$ - gross fall of $250 \mathrm{~m} ; 6$ - gross fall of $300 \mathrm{~m}$.

The decrease of the flow speed from 5 to $2.5 \mathrm{~m} / \mathrm{s}$ determines drops of hydraulic losses below $20 \%$, even for a flow of $2 \mathrm{~m}^{3} / \mathrm{s}$. This has been possible through increasing the inner diameter of the pipe from 
$0.7 \mathrm{~m}$ to $1.0 \mathrm{~m}$. Under such circumstances, data show that the hydro-electrical planning is efficient. The diagrams with the results are presented in Figure 1 (Cogălniceanu, 1986).

\section{Aligning and transporting the pipe segment along the inclined plan}

The construction technologies of power tunnels have shown that an important issue that comes out on construction sites is the transportation along an inclined plan and the alignment of pipe segments. In order to be able to solve this issue Solid Edge software has been employed for the 3D modelling and designing of the transportation sled and for aligning the pipe segment (Rades, 2006).

The framework of the sled has been made of U20 laminated profiles with two $6500 \mathrm{~mm}$ struts and four stiffening beams. Central crossbeams are made of two U20 profiles enforced in their inner part by way of $12 \mathrm{~mm}$ metal plates. Two cuttings are made within the crossbeam and the enforcing plate that allow the gliding of the $\varnothing 80$ bolt.

In its lower part the framework includes four guides that allow its gliding along the railroad. The upper part includes two crossbeams made of U20 profiles, which are centred in accordance with the central crossbeams of the framework. They are designed with a view to fix and support the supporting arm through the $\varnothing 70$ bolt. G3" pipes located at the end allow the fixing of the cable on the pipe segment. Two holds, put together through welding, for towing the sled, are located on the crossbeams at the end of the framework, in the upper part (Priscu, 1982).

With a view to settling the size and checking the sled, a 3D modelling of a $\varnothing 2550 \times 25$ pipe segment measuring $6 \mathrm{~m}$ in length has been designed. One meter from the section's edge the supporting arm has been located as in Figure 3. Owing to Solid Edge software, the mass and position of the centre of gravity of the group have also been determined. Its mass represents $10,793 \mathrm{~kg}$, while its mass centre is located at $2,770.6 \mathrm{~mm}$ from the edge and $34.6 \mathrm{~mm}$ under the axe of the section (green point). Figure 2 displays the 3D model of the constructive solution of the sled (Preluschek, 1996).
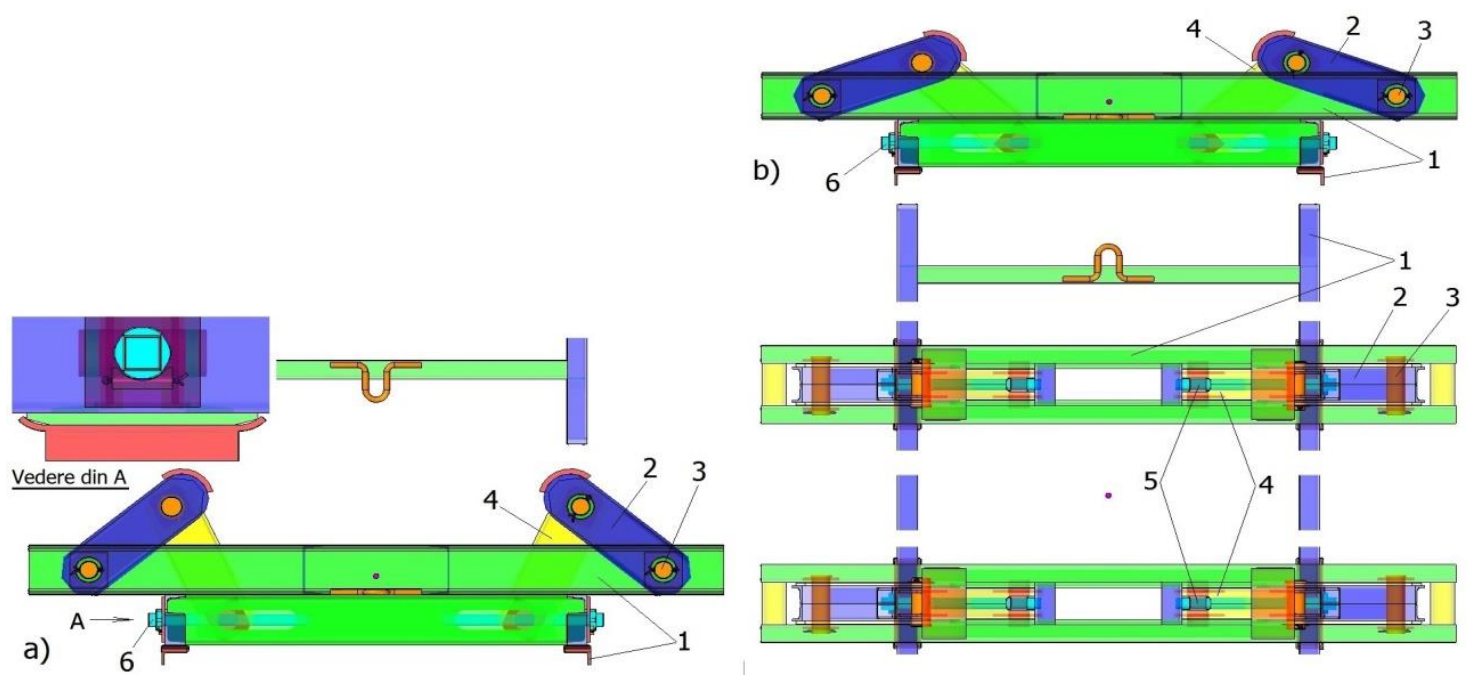

Figure 2. Constructive solution of the transportation and alignment sled of the pipe segment; $a-$ supporting arms set up at their maximum. $b$-supporting arms set down at their maximum; 1 -sled's framework; 2 - supporting arm; 3 - Ø60 bolt; 4 -lifting arm; 5 - Ø80 bolt; 6 -threaded rod M48. 
Figure 3 displays the constructive solution of the M48 threaded rod, and the Figure 4 shows the 3D model of the pipe segment.

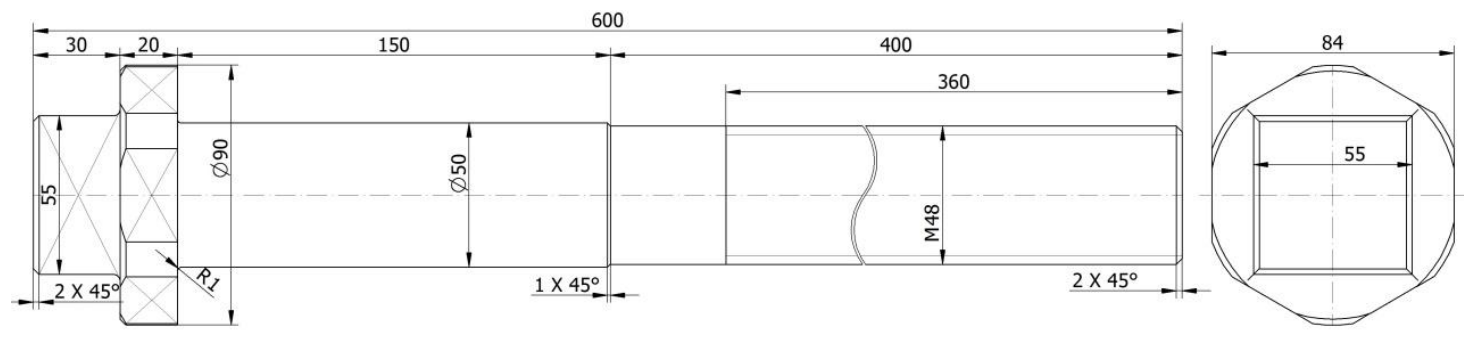

Figure 3. M48 threaded rod.
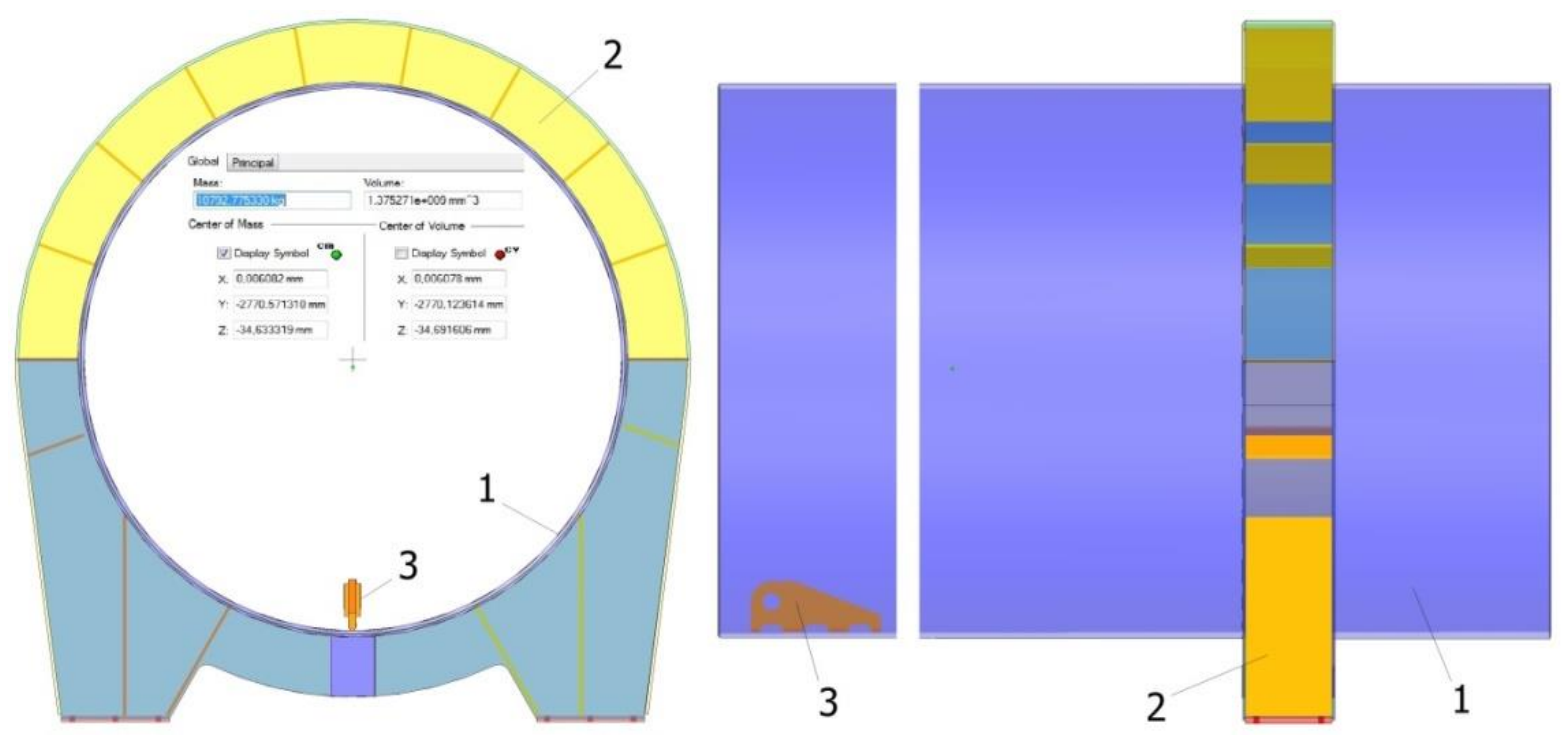

Figure 4. 3D model of the pipe segment with its supporting arm

1 - Ø2550 $\times 25 \mathrm{~mm}$ and $6 \mathrm{~m}$ length pipe segment; 2 - metal construction of the support of the pipe's segment; 3 - towing hold

With a view to obtain the maximal moment of tightening, in the case of a $0.3 \mathrm{~m}$ force arm, a maximal force of $40 \mathrm{daN}$ is required. Such a force comes out when the supporting arm is located in its minimal position. The value of the safety coefficients is higher than 3, value which is stipulated by PTR $16-$ 2003 technical prescription regarding transportation devices on inclined plans.

The $\varnothing 80 \times 200$ bolt that exerts its action upon the lifting arm has been checked at bending. A tension of $85.09 \mathrm{~N} / \mathrm{mm}^{2}$ and a safety coefficient of 3.17 result in the case of OL 50 STAS 500/2-80 steel (flow limit $\sigma \mathrm{c}=270 \mathrm{~N} / \mathrm{mm}^{2}$ ).

Figure 5 shows the analysis with finite element of the bolt, maximal tension representing 52.79 $\mathrm{N} / \mathrm{mm}^{2}$ and maximal deformation representing $0.007 \mathrm{~mm}$. This happens due to the concentration of the towing force of $40720 \mathrm{~N}$ within the axis of the threaded hole. Meanwhile, the size of the discretization element of $5 \mathrm{~mm}$ is too large. 

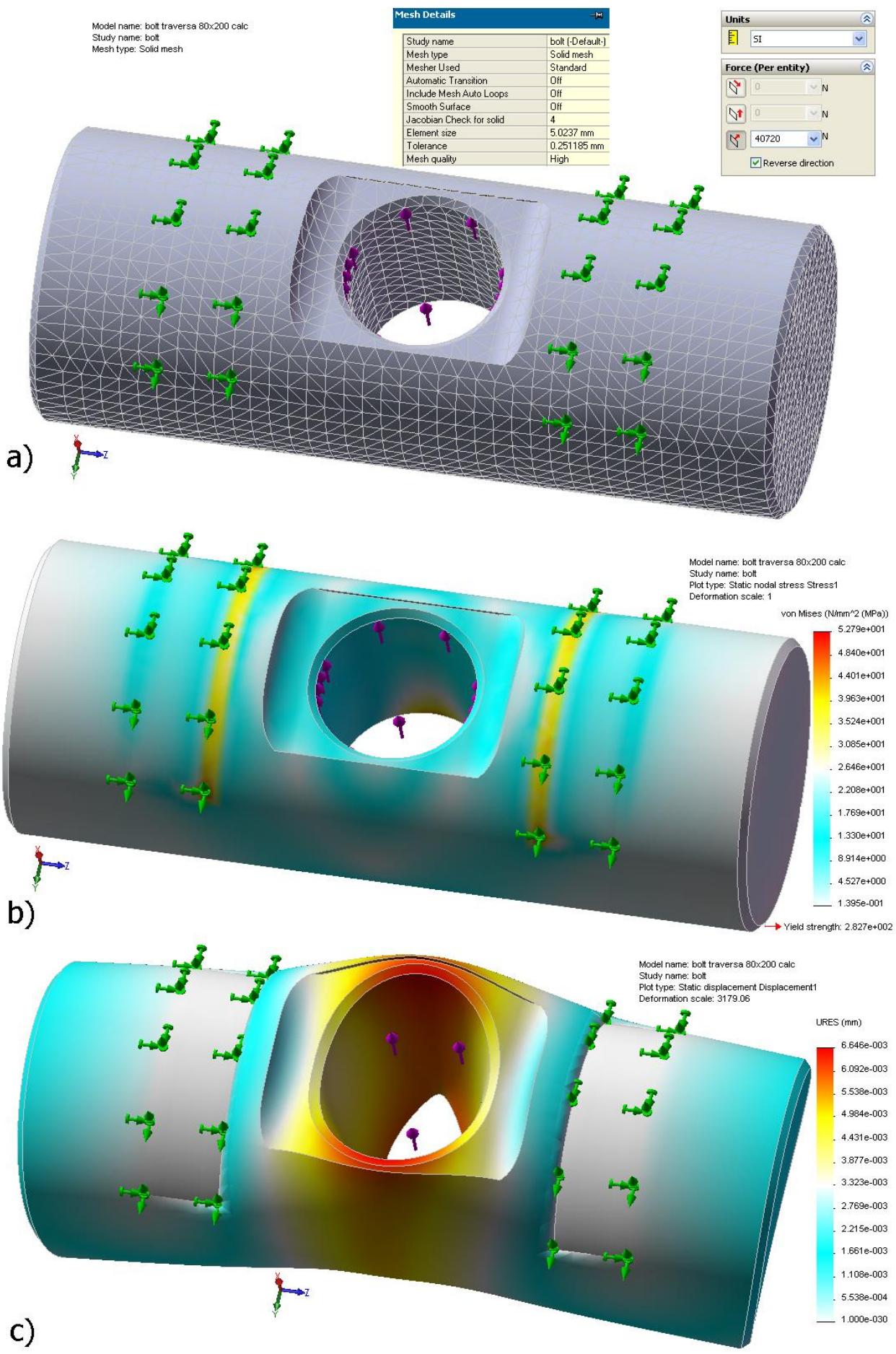

Figure 5. Analysis with finite element of $\varnothing 80 \times 200$ bolt; $a$-discretization and stress of the bolt; $b-$ equivalent tension; $c$-deformation of the bolt. 


\section{Summary}

The first issue this study has settled is the one regarding the optimal size of power tunnels. In order to solve the issue a MathCAD program has been designed, which allows the determination of the optimal inner size of the power tunnel relying on the available hydraulic power of the hydro-electric planning.

The program is able to show the hydraulic power depending on the installed flow and gross fall, for various speeds of water flow.

The inner diameter of the pipe is also determined depending on flow and fall, while considering the economic aspect of the investment at disposal. The calculated thickness of the pipe's wall corroborated with the inner diameter allows the determining of the geometrical and resistance characteristics that provide the checking of the resistance of the pipe's welding.

The assembling technology settles the length of the pipe segments depending on mass, gauge and maneuver space, the devices and equipment required for transporting and handling the pipe segments, the assembling technology through head to head welding of the pipe segments.

The calculation program may be employed for concrete cases of planning along an established route of the pipe or for planning micro-hydropower plants with installed flows less than $10 \mathrm{~m}^{3} / \mathrm{s}$.

The second important issue the study has settled regards the conceiving and designing of the sled for transportation on an inclined plan and the alignment of the pipe segment. In accordance, the constructive and functional elements of the sled as well as the checking of its resistance have been determined.

\section{References}

[1] Bâla, M., ş.a. (1981). Construcţii hidrotehnice subterane, calcul şi execuţie, vol. 1 and 2, Technical Publishing House, Bucharest.

[2] Stematiu, D. (2008). Amenajări hidroenergetice, Conspress Publishing House, Bucharest.

[3] Cogălniceanu, A., (1986). Bazele tehnice şi economice ale hidroenergeticii, Technical Publishing House, Bucharest.

[4] Rades, M. (2006). Analiza cu element finit, Editura Tehnica, Bucharest.

[5] Priscu, R. (1982). Construcţii hidrotehnice, Vol. I, Vol. II, Didactic and Pedagogical Publishing House, Bucharest.

[6] Preluschek, E. (1996). Tehnologia lucrărilor de construcţii hidrotehnice, vol.3, Polytechnic University of Timisoara, Faculty of Hydro-technique.

[7] Solid edge software V.19. Academic license ADA Computers Bucharest.

[8] Mathcad 14. Academic license ADA Computers Bucharest. 